\title{
Comparison of HER-2 overexpression in primary breast cancer and metastatic sites and its effect on biological targeting therapy of metastatic disease
}

\author{
J Zidan*, I,2, I Dashkovsky ${ }^{3}$, C Stayerman ${ }^{4}$, W Basher', C Cozacov ${ }^{3}$ and A Hadary ${ }^{3}$ \\ 'Oncology Unit, Sieff Government Hospital, Safed, Israel; ${ }^{2}$ Faculty of Medicine, Israel Institute of Technology (Technion), Haifa, Israel; ${ }^{3}$ Department of \\ Surgery, Sieff Government Hospital, Safed, Israel; ${ }^{4}$ Department of Pathology, Sieff Government Hospital, Safed, Israel
}

\begin{abstract}
HER-2 overexpression, a predictive marker of tumour aggressiveness and responsiveness to therapy, occurs in 20-30\% of breast cancer. Although breast cancer is a heterogeneous disease, HER-2 measurement is carried out in primary tumour. This study aims to evaluate HER-2 overexpression in primary and metastases and its effect on treatment decisions. Biopsies from primary breast cancer and corresponding metastases from 58 patients were studied. HER-2 overexpression was evaluated immunohistochemically in all primary and metastatic sites. Positive overexpression in primary and/or metastases was confirmed by fluorescence in situ hybridisation (FISH). Discordance in HER-2 overexpression between primary and metastatic sites was 14\% (eight of 58 patients). Concordance was found in 50 (86\%) of patients (95\% Cl: 77-95). In one patient (2\%), HER-2 was negative in metastasis but positive in primary. In seven ( $12 \%$ ) patients, HER-2 was positive in metastases and negative in primary ( $95 \% \mathrm{Cl}: 3.7-20)$, and three of them responded to trastuzumab. Gene amplification by FISH was found in all cases with HER-2 positive $(+2$ and +3$)$ by immunohistochemistry. Our data suggest that a possible discordance of HER-2 overexpression between primary and metastases should be considered when making treatment decisions in patients with primary HER-2-negative tumours.

British Journal of Cancer (2005) 93, 552-556. doi:I0.I038/sj.bjc.6602738 www.bjcancer.com
\end{abstract}

Published online 16 August 2005

(c) 2005 Cancer Research UK

Keywords: comparison; HER-2 overexpression; metastases; primary breast cancer; treatment

The choice of therapy for treatment of breast cancer is based on tumour stage, histopathologic features, hormone receptor status and biological markers (Hamilton and Piccart, 2000). The most promising biological marker in terms of predicative value for breast cancer treatment is HER-2 (Thor et al, 1998). The HER-2 oncoprotein is a transmembrane receptor, belonging to the epidermal growth factor receptor family, with tyrosine kinase activity, resulting in intracellular signalling and activation of genes involved in cell growth, which is associated with shortened survival, enhanced aggressiveness and other poor prognostic factors (Slamon et al, 1987; Tsuda et al, 1989). Most of the literature reports a correlation between HER-2 overexpression and increased sensitivity to anthracycline-based chemotherapy in comparison with CMF and tamoxifen (Elledge et al, 1998; Paik et al, 1998). Most importantly, HER-2 overexpression identifies the subset of patients who can benefit from trastuzumab, recombinant humanised anti-HER-2 monoclonal antibody (Genentech Inc., South San Francisco, CA, USA), in advanced and metastatic breast cancer (MBC) (Hortobagyi, 2001; Lohrisch and Piccart, 2001). Monotherapy with trastuzumab has yielded response rates of $35 \%$ when given as first-line therapy and $18 \%$ in patients previously treated with chemotherapy (Cobleigh, 1999; Vogel et al, 2001). Compared with chemotherapy alone, combination of chemotherapy and trastuzumab improves response rates and overall survival

*Correspondence: Dr J Zidan; E-mail: zidan.@@iv.health.gov.i Received II January 2005; revised 19 May 2005; accepted I 3 July 2005; published online 16 August 2005 for women with HER-2-positive MBC (Lohrisch and Piccart, 2001). Breast cancer is a heterogeneous tumour with high individual variability as far as response to treatment is concerned (Harris et al, 1997).

Generally, assessment of HER-2 is performed in the primary tumour even if the metastases appear several years later. As biopsy of metastases is not routine, it is difficult to test a large number of cases. Clinical metastases may grow from micrometastases resistant to adjuvant therapy and may represent one particularly aggressive clone from among many clones of primary breast cancer (Harris et al, 1997). It is still unknown whether HER-2 expression differs in metastases compared to primary breast cancer. Few data have been published regarding this issue (Cardoso et al, 2001).

The objective of the present study is to determine the expression of HER-2 in the primary breast cancer and its metastases and to update our previous results by studying additional patients (Zidan et al, 2002). All tumours and their metastases were evaluated for HER-2 using immunohistochemistry (IHC) (Hercept Test). The fluorescence in situ hybridisation (FISH) test was utilised for HER2-overexpressing cases. In addition, we examined the utility of evaluating HER-2 overexpression in metastases on the decision to treat these patients with trastuzumab. A comprehensive review of the literature was also performed.

\section{MATERIALS AND METHODS}

Between 1990 and 2002, 209 patients with MBC were treated in our department. Patients were enrolled in this study if tumour samples 
from both primary and corresponding metastases were available and suitable for IHC analysis. Patients with metastatic ipsilateral axillary lymph nodes at the primary operation were excluded.

Formalin-fixed paraffin-embedded samples of primary breast cancer and metastases were collected from 58 patients. For each case, the primary tumour and the corresponding metastases were sampled for HER-2 staining at the same time by the same two experienced pathologists. Immunohistochemical staining for HER2 was performed by using CB11 monoclonal antibody with antigen retrieval. Expression was scored using the scoring system outlined in the DAKO Hercept Test as $0,1+, 2+$ and $3+$ according to the standardised criteria (Slamon et al, 1989). Gene amplification by FISH was tested in all cases where the primary tumour or metastases were positive $(+2$ or +3$)$ by IHC.

\section{Statistical analysis}

Rates and positivity were compared using McNamara tests for paired data. Confidence intervals for concordance/discordance rates were calculated. The Kendall's tau- $b$ coefficient was used to assess concordance for HER-2 status. Although the difference between HER-2 overexpression in the primary tumour and the metastases was marginally significant $(P=0.07)$, a discordance was observed (Kendall's tau- $b$ coefficient $=0.69,95 \% \mathrm{CI}=0.53-0.80$ ) due to more cases of HER-2 overexpression in the metastases. Two-tailed $P$-values of 0.05 or less was considered to have a statistical significance.

\section{RESULTS}

All 58 cases with available biopsies from the primary tumour and metastases were included in this study. Median age at diagnosis of the primary breast cancer was 56 years (range: $29-82$ years). One patient was male. Metastases were found in bone of $68 \%$ of patients $(n=39)$, in skin and soft tissue in the surgical scar region of $35 \%$ $(n=20)$, in $36 \%(n=21)$ in liver, in lungs of $33 \%(n=19)$ of patients and in the pleura of $19 \%(n=11)$ of patients. In $35 \%$ $(n=20)$ of patients, there was one metastatic site, in $41 \%(n=24)$ of patients two sites were found and in $24 \%(n=14)$ three metastases were found (Table 1). Invasive ductal carcinoma was diagnosed in $88 \%$ of patients. Oestrogen and progesterone receptors (ER, PR) were positive in 60 and $53 \%$ of the primary tumours, respectively. All patients underwent surgery at diagnosis: $60 \%(n=35)$ of patients had lumpectomy and $40 \%(n=23)$ had mastectomy. In all, $29(50 \%)$ patients were treated with tamoxifen as adjuvant treatment with or without chemotherapy.

Metastases were diagnosed between 1 and 12 years after primary breast cancer surgery (median: 4.5 years). HER-2 was positive by IHC in $24 \%(n=14)$ of the primary breast cancer tissues (two with $2+$ and 12 with $3+)$ and negative in the remaining $76 \%(n=44)$. In $35 \%(n=20)$ of patients, HER-2 was positive in metastases (two with $2+$ and 18 with $3+)$. Of the total 58 patients, $86 \%(n=50)$ revealed a concordance between the primary tumour and its metastases (95\% CI: $77-95)$. In $2 \%$ of patients $(n=1)$, HER-2 was positive in the primary tumour and negative in the metastatic site. In $12 \%(n=7)$ of patients, HER-2 was negative in the primary tumour and positive in the corresponding metastases (95\% CI: 3, $7-20)(P=0.07)$ (Table 2). The single patient with HER-2 positive in primary carcinoma of breast and negative in skin and bone metastases was a 48-year-old woman in whom metastases were diagnosed 2 years postmastectomy. Trastuzumab and vinorelbine were given as second-line therapy for 3 months then stopped because of disease progression.

Four patients were treated with trastuzumab due to HER-2 evaluation in the metastases as follows:

Case 1: A 32-year-old male patient had metastases in skin, bone and lung 3 years after mastectomy. HER-2 was negative in the
Table I Patient characteristics

\begin{tabular}{|c|c|c|}
\hline & Number of patients & $\%$ \\
\hline Total number of patients & 58 & 100 \\
\hline \multicolumn{3}{|l|}{ Gender } \\
\hline Female & 57 & 98 \\
\hline Male & । & 2 \\
\hline \multicolumn{3}{|l|}{ Age (years) } \\
\hline Median & 56 & \\
\hline Range & $29-82$ & \\
\hline \multicolumn{3}{|l|}{ Receptor status, primary tumour } \\
\hline ER positive & 35 & 60 \\
\hline PR positive & 31 & 53 \\
\hline \multicolumn{3}{|l|}{ Primary surgery } \\
\hline Lumpectomy & 35 & 60 \\
\hline Mastectomy & 23 & 40 \\
\hline \multicolumn{3}{|l|}{ Histology } \\
\hline Invasive ductal carcinoma & 51 & 88 \\
\hline Invasive lobular carcinoma & 7 & 12 \\
\hline \multicolumn{3}{|l|}{ Number of metastatic sites } \\
\hline I & 20 & 35 \\
\hline 2 & 24 & 41 \\
\hline 3 & 14 & 24 \\
\hline \multicolumn{3}{|l|}{ Prior therapy } \\
\hline Adjuvant chemotherapy & 29 & 50 \\
\hline Adjuvant hormonal therapy & 10 & 18 \\
\hline Adjuvant chemo+hormonal therapy & 19 & 32 \\
\hline
\end{tabular}

$\mathrm{ER}=$ oestrogen receptor; $\mathrm{PR}=$ progesterone receptor.

primary tumour but positive in skin and bone metastases. After failure with doxorubicin and paclitaxel, he received trastuzumab as a single agent and achieved partial response for 9 months.

Case 2: A 58-year-old woman with primary HER-2 negative but positive in metastases in liver (after 6 years) received trastuzumab monotherapy as third-line therapy after chemotherapy failure for 6 months with minimal response and no side effects.

Case 3: A 61-year-old woman had a local recurrence in skin and soft tissue of chest wall 5 years after mastectomy. Oestrogen receptor and PR were positive. She received tamoxifen as an adjuvant treatment for 5 years. At the end of the 5 th year, she was diagnosed with multiple local recurrences in skin and soft tissue. HER-2 was negative in the primary and positive $(+2)$ in the recurrence. Gene amplification by FISH was negative in the primary and positive in the recurrence. ER and PR were found to be positive in the recurrence as well. After chemotherapy failure (two lines), the patient received trastuzumab with vinorelbine weekly, achieving complete response after 5 months. For the past 13 months, this patient has received only trastuzumab and still in complete remission with high quality of life.

Case 4: A 52-year-old woman with lung metastases with HER-2 negative in primary and positive in metastases did not respond to trastuzumab therapy. Three deceased patients who had not received trastuzumab were studied retrospectively.

\section{DISCUSSION}

The most promising predictive factor for breast cancer today is HER-2. Breast tumours with HER-2 overexpression are resistant to hormonal therapy and alkylating agents, but more sensitive to anthracycline-based chemotherapy (Elledge et al, 1998; Ross and 
Table 2 Comparison of 21 patients with HER-2 positive in primary breast cancer and/or metastatic site

\begin{tabular}{|c|c|c|c|c|c|}
\hline Case \# & $\begin{array}{l}\text { HER-2 (IHC) in } \\
\text { primary }\end{array}$ & $\begin{array}{l}\text { HER-2 (FISH) in } \\
\text { primary }\end{array}$ & Metastatic site & $\begin{array}{l}\text { HER-2 (IHC) in } \\
\text { metastases }\end{array}$ & $\begin{array}{l}\text { HER-2 (FISH) in } \\
\text { metastases }\end{array}$ \\
\hline 1 & +3 & Positive & Skin, soft tissue & +3 & Positive \\
\hline 4 & +3 & Positive & Pleura & +3 & Positive \\
\hline 5 & +3 & Positive & Liver & +3 & Positive \\
\hline 8 & +3 & Positive & Skin & +3 & Positive \\
\hline 9 & +3 & Positive & Bone & +2 & Positive \\
\hline 10 & +3 & Positive & Lung & +3 & Positive \\
\hline 11 & +2 & Positive & Bone & +3 & Positive \\
\hline 12 & +3 & Positive & Skin & +3 & Positive \\
\hline 13 & +3 & Positive & Liver & +3 & Positive \\
\hline 14 & +3 & Positive & Skin and bone & Negative & Negative \\
\hline 20 & Negative & Negative & Pleura & +3 & Positive \\
\hline 21 & Negative & Negative & Lung & +3 & Positive \\
\hline
\end{tabular}

$\mathrm{IHC}=$ immunohistochemistry; FISH = fluorescence in situ hybridisation.

Fletcher, 1998; Hamilton and Piccart, 2000). Studies that have addressed HER-2 as a predictive factor for hormonal therapy have demonstrated lower response rates or reduced survival in hormonally treated patients whose tumours overexpressed HER2 (level $2+$ or $3+$ ), reaching statistical significance in most studies (Nicholson et al, 1993; Leitzel et al, 1995; Elledge et al, 1998).

HER-2 overexpression is gaining acceptance as an indicator that defines breast cancer patients who should preferentially receive anthracycline-based or CMF adjuvant or therapeutic treatment (Paik et al, 1998; Thor et al, 1998; Hamilton and Piccart, 2000; Andrulis et al, 1998). HER-2 overexpression is a prerequisite for treating patients with $\mathrm{MBC}$ with trastuzumab, and may be considered for adjuvant treatment in the future (Ross and Fletcher, 1998; Baselga, 2001; Eiermann, 2001).

Generally, evaluation of HER-2 overexpression for the treatment of $\mathrm{MBC}$ is carried out in the primary tumour. Overexpression is shown in $20-77 \%$ of human breast cancers (Slichenmyer and Fry, 2001). Modern diagnostic techniques and tumour markers can detect metastases without the need for routine biopsy of metastases. On the other hand, axillary lymph node dissection is a standard procedure of surgical treatment of breast cancer. This makes the evaluation of HER-2 in metastases difficult compared to primary breast cancer and axillary lymph nodes. Most studies occurred over a period of years because of the difficulty in recruiting patients (Gancberg et al, 2002). Cardoso et al (2001) evaluated HER-2 overexpression in primary breast cancer and metastatic axillary lymph nodes in 370 patients. HER-2 was positive in $10 \%$ of the primary and $11 \%$ of the metastases. In all, $98 \%$ of these patients revealed a concordance between primary tumour and lymph nodes.

Distant metastases should not be assumed to be biologically equivalent to lymph node metastases. Distant metastases are generally identified years after resection of the primary cancer and axillary lymph nodes, and represent clonal outgrowths with genetic modifications not detected in the primary tumour. Additionally, cells that metastasise via the lymphatic system may possess biological properties that permit travel to distant sites and establishment of clinically disseminated disease (Harris et al, 1997).
The present study suggests a $14 \%$ discordance of HER-2 overexpression between primary tumour and the metastases $(P=0.07$ McNamara). HER-2 was positive in the primary and negative in the metastatic site in one patient $(2 \%)$ and negative in the primary and positive in metastases in seven patients (12\%). In these seven patients, findings affected the selection of therapy, particularly by trastuzumab, in four who otherwise would not have been selected for trastuzumab treatment.

A review of the literature found only 11 studies comparing HER-2 overexpression in primary breast cancer and metastases (Table 3). These studies show discordance rates of between 0 and 26\%. Niehans et al (1993) retrospectively evaluated HER-2 overexpression in primary breast cancer and different metastatic sites in autopsy tumour samples. The uncontrolled fixation time of autopsy samples jeopardises the IHC data that can be obtained from samples. Masood and Bui (2000) evaluated HER-2 overexpression in 56 patients, but only 11 cases of metastases were from distant sites. At the 2000 San Antonio Breast Cancer Meeting, Edgerton et al (2000) presented preliminary results of a study comparing HER-2 status in 193 patients, only 93 of which were distant metastases. Only seven of the 21 metastatic samples evaluated by Shimizu et al (2000) were from distant sites. Tanner et al (2001) reported on 46 primary breast cancers and their metastases. Only 12 of the 46 cases were metastases from distant sites. Gancberg et al (2002) utilised both IHC and FISH techniques retrospectively in 107 patients between 1991 and 1999. Only 68 out of the 107 cases were available for FISH test and five (7\%) of them were discordant. In our previous study, 40 patients with primary and metastases were evaluated by IHC test. Discordance was found in $18 \%$ of cases (Zidan et al, 2002) and in $14 \%$ when 58 patients were evaluated using both IHC and FISH (Zidan et al, 2004). Dowsett et al (2003) reported on $8 \%$ discordance. In the study presented by Lipton et al (2003), serum was obtained at the time of disease progression from 240 patients who were initially serum HER-2 negative at the start of hormone therapy. In 62 (26\%) of 240 patients, serum HER-2 converted from negative to positive at the time of disease progression. Luftner et al (2004) found discordance in $18 \%$ of 80 cases using IHC. An analysis of the studies summarised in Table 3 shows that the seven studies with the largest number of patients found discordance to be $\geqslant 7$ to $26 \%$ and 
Table 3 Studies comparing HER-2 overexpression in primary breast cancer and distant metastases

\begin{tabular}{|c|c|c|c|}
\hline Investigator & \# of pts. & $\begin{array}{l}\text { HER-2 } \\
\text { overexpression: } \\
\text { evaluation } \\
\text { method }\end{array}$ & $\begin{array}{c}\text { Discordance (\%) } \\
\text { in HER-2 } \\
\text { between } \\
\text { primary and } \\
\text { metastasis }\end{array}$ \\
\hline Neihans & 30 & $\mathrm{HC}$ & 3 \\
\hline Masood & 56 & $\mathrm{HC}$ & 2 \\
\hline Edgerton & 193 & $\mathrm{IHC}$ and $\mathrm{FISH}$ & 25 \\
\hline Shimizu & 21 & $\mathrm{HHC}$ & 0 \\
\hline Tanner & 46 & $\mathrm{IHC}$ and $\mathrm{ClSH}$ & 0 \\
\hline Gancberg & 107 & $\mathrm{IHC}$ and $\mathrm{FISH}$ & 7 \\
\hline Zidan & 40 & $\mathrm{HC}$ & 18 \\
\hline Zidan & 58 & $\mathrm{IHC}$ and $\mathrm{FISH}$ & 14 \\
\hline Dowsett & 39 & $\mathrm{HC}$ & 8 \\
\hline Lipton & 240 & Serum ECD & 26 \\
\hline Luftner & 80 & $\mathrm{HC}$ & 18 \\
\hline
\end{tabular}

$\mathrm{IHC}=$ immunohistochemistry; FISH = fluorescence in situ hybridisation; $\mathrm{CISH}=$ chromogenic in situ hybridisation; ECD = extracellular domain.

four studies showed a discordance rate of $0-3 \%$. These four studies were actually based on small numbers of distant metastases and include mostly locoregional relapses.

Immunohistochemistry staining has certain limitations, this cannot, however, explain the discordance observed between primary and metastases in the expression of HER-2 in the present study. The same IHC method was used for all patients and evaluation was carried out by the same pathologist. Primary and metastatic lesions from the same patients were immunostained in the same staining run, thus the probability of error is minimised.

The best method of measuring HER-2 is a point of controversy. A consensus conference was held in August 1999 in an attempt to resolve some of these issues (Author unlisted, 1999). Data presented at that meeting indicate that the concordance between IHC and FISH methods is in the range of $80-90 \%$, comparing $3+$ overexpression. As the median time between primary tumour and metastases in our study is 4.5 years, it is difficult to compare HER2 overexpression by using frozen tissue samples from both primary and metastases. This technical limitation may affect the results of IHC test for HER-2 expression in some cases. FISH technique was used for testing and confirming all cases with HER2 overexpression by IHC $(+2$ and +3$)$. All cases in our study showed amplification by FISH. The first limitation of FISH is the much higher cost when compared to IHC test. The second limitation is that, although IHC can be carried out in nearly every pathology laboratory, FISH can be performed only in special laboratories with specialised equipment.

The present study is one of the first to address the issue of heterogeneity between breast cancer primaries and metastatic sites. The rationale behind the present study is the fact that breast cancer is a biologically and genetically heterogeneous tumour that contains multiple different clones (Teixeira et al, 1995). An early stem line clone may migrate to the metastatic site and grow independently from its counterpart in the primary tumour, resulting in complete heterogeneity between primary and metastatic sites in the same patient. Heterogeneity between primary and metastatic sites may also result from the genetic instability of cancer cells. Breast cancer cells that survive adjuvant treatment may undergo genetic changes resulting in either a loss or gain of expression of some biological markers (Kuukasjarvi et al, 1997). Molecular changes, including upregulation of HER-2, were observed in breast cancer relapsing after adjuvant hormone therapy (Slichenmyer and Fry, 2001; Tanner et al, 2001). In our study, four of seven patients with HER-2 positive in metastases and negative in the primary initially received adjuvant treatment with tamoxifen before developing metastases. Two became ER negative in metastases. Additionally, some small clones in the primary tumour overexpress HER-2, but are negligible in the tumour mass and may not be detected in the staining of the larger primary breast cancer. Metastases developing from such clones are HER-2 positive (Teixeira et al, 1995).

In all, $12 \%$ of patients in the current study were found to be eligible for treatment with trastuzumab, according to results of HER-2 overexpression in metastatic sites. To our knowledge, ours is the first study to address the possibility of treating patients with metastases of breast cancer with trastuzumab based on the discordance in HER-2 overexpression between primary tumour and metastases.

Three other techniques appear easy and applicable in evaluating HER-2 overexpression in MBC. One promising method is the testing of extracellular domain of HER-2 in serum of breast cancer patients (Burstein et al, 2003). Another technique is the evaluation of HER-2 amplification by chromogenic in situ hybridisation. This technique is easy, inexpensive and can be carried out in most hospitals (Dandachi et al, 2004). HER-2 amplification detected by FISH in fine-needle aspiration (FNA) from metastases is also a promising technology. Bozzetti et al (2002) evaluate HER-2 amplification by FISH on 66 breast cancer FNAs. Paired results by FISH cytology and FISH histology showed a concordance of $91 \%$. They concluded that HER-2 gene amplification can be reliably estimated by FISH on breast cancer FNAs. This makes the evaluation of HER-2 from metastases easy and implementable.

To summarise, the present study demonstrates a relatively high discordance rate (14\%) in HER-2 overexpression between primary and metastases of the same breast cancer, emphasising the existence of biological differences between primary and metastases. We suggest taking HER-2 evaluation into consideration in metastatic sites when HER-2 is negative in the primary tumour and the patient can benefit from treatment with trastuzumab. Additional studies with larger numbers of patients are needed to verify our results.

\section{ACKNOWLEDGEMENTS}

Funding for this study was provided by the Israel Cancer Association. We are grateful for their support.

\section{REFERENCES}

Andrulis IL, Bull SB, Blackstein ME, Sutherland D, Mak C, Sidlofsky S, Pritzker KP, Hartwick RW, Hanna W, Lickley L, Wilkinson R, Qizilbash A, Ambus U, Lipa M, Weizel H, Katz A, Baida M, Mariz S, Stoik G, Dacamara P, Strongitharm D, Geddie W, McCready D (1998) Neu/erbB-2 amplification identifies a poor-prognosis group of women with node-negative breast cancer. Toronto Breast Cancer Study Group. J Clin Oncol 16(4): 1340 - 1349
Baselga J (2001) Phase I and II clinical trials of trastuzumab. Ann Oncol 12(Suppl 1): 49-55

Bozzetti C, Nizzoli R, Guazzi A, Flora M, Bassano C, Crafa P, Naldi N, Cascinu S (2002) HER-2/neu amplification detected by fluorescence in situ hybridization in fine needle aspirates from primary breast cancer. Ann Oncol 13: $1398-1403$ 
Burstein HJ, Harris LN, Marcom PK, Lambert-Falls R, Havlin K, Overmoyer B, Friedlander Jr RJ, Gargiulo J, Strenger R, Vogel CL, Ryan PD, Ellis MJ, Nunes RA, Bunnell CA, Campos SM, Hallor M, Gelman R, Winer EP (2003) Trastuzumab and vinorelbine as first-line therapy for HER2overexpressing metastatic breast cancer: multicenter phase II trial with clinical outcomes, analysis of serum tumor markers as predictive factors, and cardiac surveillance algorithm. J Clin Oncol 21: 2889-2895

Cardoso F, Di Leo A, Larsimont D, Gancberg D, Rouas G, Dolci S, Ferreira F, Paesmans M, Piccart M (2001) Evaluation of HER2, p53, bcl-2, topoisomerase II-alpha, heat shock proteins 27 and 70 in primary breast cancer and metastatic ipsilateral axillary lymph nodes. Ann Oncol 12: 615-620

Cobleigh M, Vogel CH, Tripathy D (1999) Multinational study of the efficacy and safety of humanized anti-HER2 monoclonal antibody in women who have HER2 overexpressing metastatic breast cancer that has progressed after chemotherapy for metastatic disease. J Clin Oncol 17: $2639-2648$

Dandachi N, Dietze O, Hauser-Krongberg C (2004) Evaluation of the clinical significance of HER-2 amplification by chromogenic in situ hybridization in patients with primary breast cancer. Anticancer Res 24: $2401-2406$

Dowsett M, Gutierrez C, Mohsin S, Schiff R, Detre S, Johnston S, Osborne CK (2003) Molecular changes in tamoxifen-relapsed breast cancer: relationship between ER, HER2, and p38 MAP-Kinase. Proc Am Soc of Clin Oncol 22: 3 (Abstract 7)

Edgerton SE, Merkel D, Moore DH, Thor AD (2000) HER-2/neu/erB-b2 status by immunohistochemistry and FISH: clonality and progression with recurrence and metastases. Breast Cancer Res Treat 64: 55

Eiermann W (2001) The International Trastuzumab Study Group. Trastuzumab combined with chemotherapy for the treatment of HER-2 positive metastatic breast cancer: pivotal trial data. Ann Oncol 12(Suppl 1): $57-62$

Elledge R, Green S, Ciocca D, Pugh R, Allred DC, Clark GM, Hill J, Ravdin P, O'Sullivan J, Martino S, Osborne CK (1998) HER-2 expression and response to tamoxifen in estrogen receptor-positive breast cancer: a Southwest Oncology Group Study. Clin Cancer Res 4: 7-12

Gancberg D, Di Leo A, Cardoso F, Rouas G, Pedrocchi M, Paesmans M, Verhest A, Bernard-Marty C, Piccart MJ, Larsimont D (2002) Comparison of HER-2 status between primary breast cancer and corresponding distant metastatic sites. Ann Oncol 13: 1036-1043

Hamilton A, Piccart M (2000) The contribution of molecular markers to the prediction of response in the treatment of breast cancer: a review of the literature on HER-2, p53 and BCL-2. Ann Oncol 11: 647-663

Harris J, Morrow M, Norton L (1997) Malignant tumors of the breast. In Cancer: Principles and Practice of Oncology, DeVita Jr VT, Hellman S, Rosenberg SA (eds), 5th edn pp 1557-1616. Philadelphia: LippincottRaven

Hortobagyi G (2001) Optimal duration therapy with trastuzumab. Semin Oncol 28(Suppl 18): 1-2

Kuukasjarvi T, Karhu R, Tanner M, Kahkonen M, Schaffer A, Nupponen N, Pennanen S, Kallioniemi A, Kallioniemi OP, Isola J (1997) Genetic heterogeneity and clonal evolution underlying development of asynchronous metastasis in human breast cancer. Cancer Res 57: 1597-1604

Leitzel K, Teramoto Y, Konrad K, Chinchilli VM, Volas G, Grossberg H, Harvey H, Demers L, Lipton A (1995) Elevated serum c-erb-B2 antigen levels and decreased response to hormone therapy of breast cancer. J Clin Oncol 13: 1129-1135

Lipton A, Leitzel K, Ali SM, Demers L, Harvey HA, Chaudri-Ross HA, Lang R, Hackl W, Hamer P, Carney W (2003) Serum HER-2/neu conversion to positive at the time of cancer progression in metastatic breast patients treated with letrozole $v s$ tamoxifen. Proc Am Soc Clin Oncol 22: 3 (Abstract 8)

Lohrisch C, Piccart M (2001) An overview of HER-2. Semin Oncol 28(Suppl 18): 3-11

Luftner D, Dilk H, Henschke P, Geppert R, Dietel M, Stein H, Wernecke K, Possinger K, Heine P (2004) Results of a 10-year retrospective search in two university institutes of pathology: Concordance of HER-2/neu expression of primary breast carcinomas and their metachronous distant metastases. Proc Am Soc Clin Oncol 23(14S): 44 (Abstract 670)

Masood S, Bui MM (2000) Assessment of HER-2/neu overexpression in primary breast cancers and their metastatic lesions: an immunohistochemical study. Ann Clin Lab Sci 30: 259-265

Nicholson RI, McClelland RA, Finlay P, Eaton CL, Gullick WJ, Dixon AR, Robertson JF, Ellis IO, Blamey RW (1993) Relationship between EGF-R, c-erbB-2 protein expression and Ki67 immunostaining in breast cancer and hormone sensitivity. Eur J Cancer 29A: 1018 - 1023

Niehans GA, Singleton TP, Dykoski D, Kiang DT (1993) Stability of HER-2/ neu expression over time and at multiple metastatic sites. J Natl Cancer Inst 85: $1230-1235$

No author listed (1999) Detection of HER2/neu (c-erbB-2) Antigen Overexpression: An NCI Symposium. Bethesda, MD: Lippincott, October 7-8

Paik S, Bryant J, Park C, Fisher B, Tan-Chiu E, Hyams D, Fisher ER, Lippman ME, Wickerham DL, Wolmark N (1998) erb-B2 and response to doxorubicin in patients with axillary lymph node positive, hormone receptor-negative breast cancer. J Natl Cancer Inst 90: 1361 - 1370

Ross JS, Fletcher JA (1998) The HER-2/neu oncogene in breast cancer: prognostic factor, predictive factor, and target for therapy. Oncologist 3 : $237-252$

Shimizu C, Fukutomi T, Tsuda H, Akashi-Tanaka S, Watanabe T, Nanasawa T, Sugihara K (2000) c-erbB-2 protein overexpression and p53 immunoreaction in primary and recurrent breast cancer tissues. J Surg Oncol 73: $17-20$

Slamon DJ, Clark GM, Wong SG, Levin WJ, Ullrich A, McGuire WL (1987) Human breast cancer: correlation of relapse and survival with amplification of the HER-2/neu oncogene. Science 235: 177-182

Slamon DJ, Godolphin W, Jones LA, Holt JA, Wong SG, Keith DE, Levin WJ, Stuart SG, Udove J, Ullrich A, Press MF (1989) Studies of the HER-2/ neu proto-oncogene in human breast and ovarian cancer. Science 244: $707-712$

Slichenmyer W, Fry D (2001) Anticancer therapy targeting the Erb B family of receptor tyrosine kinases. Semin Oncol 28: 67-79

Tanner M, Jarvinen P, Isola J (2001) Amplification of HER-2/neu and topoisomerase II- $\alpha$ in primary and metastatic breast cancer. Cancer Res 61: $5345-5348$

Teixeira MR, Pandis N, Bardi G, Andersen JA, Mitelman F, Heim S (1995) Clonal heterogeneity in breast cancer: karyotypic comparisons of multiple intra- and extra-tumorous samples from 3 patients. Int $J$ Cancer 63: 63-68

Thor AD, Berry DA, Budman DR, Muss HB, Kute T, Henderson IC, Barcos M, Cirrincione C, Edgerton S, Allred C, Norton L, Liu ET (1998) erbB-2, p53 and efficacy of adjuvant therapy in lymph node-positive breast cancer. $J$ Natl Cancer Inst 90: 1346-1360

Tsuda $\mathrm{H}$, Hirohashi S, Shimosato $\mathrm{Y}$, Hirota T, Tsugane S, Yamamoto $\mathrm{H}$, Miyajima N, Toyoshima K, Yamamoto T, Yokota J, Yoshda T, Skamoto H, Terada M, Sugimura T (1989) Correlation between long term survival in breast cancer patients and amplification of two putative oncogene co-amplification units: hst-1/int-2 and c-erbB-2/ear-1. Cancer Res 49: 3104-3108

Vogel C, Cobleigh M, Tripathy D, Harris L, Fehrenbacher L, Slamon D, Ash M, Novotny W, Stewart S, Shak S (2001) First-line, non-hormonal, treatment of women with HER2 overexpressing metastatic breast cancer with Herceptin (trastuzumab, humanized anti-HER2 antibody). Proc Am Soc Clin Oncol 19: 71a (Abstract 275)

Zidan J, Dashkovsky I, Cozacov C, Hadary A, Basher W (2002) Comparison of HER-2 in primary breast cancer and metastatic sites and its effect on treatment of metastatic disease. ESMO 2002 Ann Oncol 13(Suppl 5): 50 (Abstract 179P)

Zidan J, Dashkovsky I, Hadary A, Basher W, Cozacov C (2004) Comparison of HER-2 overexpression in primary breast cancer and metastatic sites and its effect on biological targeting therapy of metastatic disease. Proc Am Soc of Clin Oncol 23: 40 (Abstract 655) 